\title{
Os efeitos textuais e argumentativos dos raciocínios lógico-comparativos na formação para a pesquisa científica
}

\section{Thiago Jorge Ferreira Santos}

Doutor em Letras pela Universidade de São Paulo (USP), Brasil orcid.org/0000-0002-8857-1486

Este artigo tem por objetivo discutir a construção e os efeitos textuais-argumentativos dos raciocínios lógico-comparativos a partir das interações verbais entre orientandos e orientadores, nas versões de textos escritos ao longo da formação no mestrado acadêmico: projetos de pesquisa, relatórios de qualificação e dissertações. Adotamos como base teórica 0 interacionismo sociodiscursivo, especialmente a categoria de tipos discursivos. Primeiramente, analisaremos alguns excertos, a fim de compreender o processo de aprendizagem epistêmica por meio da modificação e reformulação das exposições teóricas dos estudantes, após os comentários dos seus orientadores. Depois, evidenciaremos que os raciocínios lógico-comparativos, encontrados nos excertos das seções de "Análises e resultados" das pesquisas, apontam a maneira pela qual os estudantes mobilizam os conceitos teóricos aprendidos ao longo do mestrado como parâmetros para organizar processos mentais de sínteses interpretativas (generalizações).

Palavras-chave: Raciocínio lógico-comparativo. Tipo discursivo. Aprendizagem epistêmica. Pensamento científico.

\section{Los efectos textuales y argumentativos de los razonamientos lógico-comparativos en la formación para la investigación científica}

Este artículo pretende discutir la construcción y los efectos textual-argumentativos del razonamientos lógico-comparativos de las interacciones verbales entre estudiantes y asesores, en las versiones de los textos escritos a lo largo de la formación en el máster académico: proyectos de investigación, informes de calificación y disertación de maestría. Adoptamos como base teórica el interaccionismo sociodiscursivo, especialmente la categoría de tipos discursivos. En primer lugar, analizaremos algunos extractos, con el fin de comprender el proceso de aprendizaje epistémico a través de la modificación y reformulación de las exposiciones teóricas de los estudiantes, tras los comentarios de sus supervisores. A continuación, destacaremos que los razonamientos comparativos, encontrados en los extractos de las secciones de "Análisis y resultados" de las investigaciones, indican la forma en que los estudiantes movilizan los conceptos teóricos aprendidos a lo largo de la maestría como parámetros para organizar procesos mentales de síntesis interpretativas (generalizaciones).

Palabras clave: Razonamiento lógico-comparativo. Tipo discursivo. Aprendizaje epistémico. Pensamiento científico.

\section{The textual and argumentative effects of logical-comparative reasoning in education for scientific research}

This article aims to discuss the construction and textual-argumentative effects of logical-comparative reasoning from the verbal interactions between students and advisors, in the versions of texts written during the academic master's degree course: research projects, qualification reports and dissertations. We adopted as theoretical basis the sociodiscursive interactionism, especially the category of discourse types. Firstly, we will analyze some excerpts in order to understand the process of epistemic learning through the modification and reformulation of the students' theoretical expositions, following their advisor's comments. Then, we will highlight that the comparative reasoning, found in the excerpts of the "Analysis and research results" sections, point to the way in which students mobilize the theoretical concepts learned throughout the master's degree as parameters to organize mental processes of interpretative syntheses (generalizations). Keywords: Logical-comparative reasoning. Discursive type. Epistemic learning. Scientific thinking. 


\section{Introdução}

Este artigo, produto de uma pesquisa de doutorado concluída, tem por objetivo geral discutir a construção dos raciocínios lógicos no processo formativo do mestrado acadêmico. Especificamente, buscaremos discutir a construção e os efeitos textuaisargumentativos dos raciocínios lógico-comparativos nas interações verbais entre orientandos e orientadores, nas versões de textos escritos na formação em mestrado acadêmico: projetos de pesquisa, relatórios de qualificação e dissertações. Para isso, será importante examinar os comentários escritos dos orientadores nas versões dos textos.

Diversos estudos já evidenciaram o caráter formativo do processo do mestrado acadêmico, porém em sua grande parte analisam-no a partir da análise de questionários, a fim de discutir a qualidade de determinado programa de pós-graduação, sejam por seus matriculados, sejam por seus egressos (SOMENSI, 2005; SILVA, 2008). Não obstante, quando os textos produzidos pelos mestrandos ao longo da formação são contemplados, não se alude à questão do papel das interações verbais formativas, tampouco se elabora uma reflexão acerca da construção dos saberes pela linguagem. ${ }^{1}$ Desse modo, a nossa pesquisa objetivou contribuir para a reflexão sobre 0 desenvolvimento do pesquisador.

Sobre os estudos em letramento acadêmico que investigam os textos e discursos científicos, Rinck (2015, p. 59) distingue dois tipos de abordagens. As primeiras questionam a atividade científica e mostram o interesse de fazê-lo por meio dos signos e textos que ela produz. As segundas descrevem as características linguísticas do discurso científico e, assim, esclarecem a atividade científica e a maneira como ela se constrói através de seus discursos. Nosso trabalho se alinha a essas abordagens, pois objetivamos analisar o processo formativo do mestrado através das interações verbais nele arroladas.

Enquadrando nosso objetivo do artigo nos estudos sobre argumentação, é preciso situá-lo neste campo investigativo. Como evidenciaremos na exposição teórica, a divisão proposta por Plantin (2008) em organizar didaticamente as abordagens de argumentação em polos (polo das boas razões e polo lógico-linguístico) é relevante, a fim de localizar o ponto de vista teórico adotado em nossa pesquisa. Adotamos como base teórica central o interacionismo sociodiscursivo (doravante ISD) (BRONCKART,

\footnotetext{
1 Em nosso estudo de doutorado (FERREIRA-SANTOS, 2020), elaboramos um levantamento de pesquisas que se focaram no mestrado acadêmico. Para isso, utilizamos a Biblioteca Digital Brasileira de Teses e Dissertações (BDTD), pois ela tem por objetivo reunir as teses e dissertações defendidas em todo o País, em um só portal de base de dados digitais. Neste, convergem as pesquisas encontradas em outras plataformas, como das Instituições de Ensino Superior, sejam públicas ou privadas, e da CAPES.
} 
1985 ; 1999; 2006) acerca do desenvolvimento humano por meio da linguagem, em nosso caso, mais precisamente do desenvolvimento do pesquisador.

Tendo em vista nosso objetivo específico, apresentaremos primeiramente o modo como o raciocínio comparativo é abordado em teorias da argumentação para, em seguida, deslindarmos sobre o ISD, enfatizando a categoria dos tipos discursivos proposta pela teoria. Depois, descreveremos os procedimentos metodológicos de nossa pesquisa e deste artigo e, enfim, exporemos nossas análises das interações verbais e os raciocínios lógico-comparativos nas versões dos textos produzidos durante 0 mestrado acadêmico.

\subsection{A comparação no polo das boas razões}

De origem aristotélica, o polo das boas razões congrega propostas que concebem a argumentação como um discurso coerente, baseado em um elemento evidente, e dele fazer derivar uma segunda proposição, isto é, apoia-se uma afirmação (a conclusão) sobre uma boa razão (o argumento). Assim, argumentar é ligar proposições (PLANTIN, 2008, p. 15).

$\mathrm{Na}$ Retórica, Aristóteles aborda o raciocínio comparativo em alguns capítulos da obra. A comparação aparece primeiramente como um tipo de "provas dos exemplos", primeira prova comum aos três gêneros (jurídico, epidítico e demonstrativo), cuja função é criar uma aproximação entre duas realidades, a fim de tornar o que se diz mais acessível (ARISTOTE, 1856, p. 231). Páginas depois, o filósofo estagirita aborda exclusivamente a comparação, definindo-a como um tipo de metáfora, porém dela se opõe ao acrescentarmos a conjunção "como", por exemplo em "Aquiles se impõe como um leão" (ARISTOTE, 1856, p. 309). No sentido aristotélico, Fiorin (2015, p. 124) afirma que as comparações têm um sentido pedagógico forte, pois dão concretude àquilo que é uma abstração.

Na Nova Retórica perelmaniana, que acentua o papel do auditório na interação discursiva, a comparação é um argumento quase lógico. Conforme explicam Perelman e Olbrechts-Tyteca (2005, p. 219), a força dos argumentos quase lógicos está diretamente relacionada com a sua proximidade, ou com a similitude da sua estrutura, dos raciocínios de tipo formal, lógico matemático. Os dois autores entendem que no raciocínio lógico-comparativo as interações entre termos de uma comparação podem ser devidas à percepção de vínculos reais entre o que se coteja (2005, p. 274). O raciocínio comparativo consiste em considerar vários elementos, situações ou objetos com vista a avaliá-los uns relativamente aos outros.

No polo das boas razões, em síntese, a comparação é, como explica didaticamente Fiorin (2015, p. 122), uma maneira de definir e aproximar ou diferenciar 
um objeto de outros, na qual não se toma o objeto em si, expondo suas características ou suas funções, mas se escolhe outro objeto mais conhecido e se faz aproximações entre eles.

\subsection{A comparação no polo lógico-linguístico}

Ancoradas nos estudos da linguística, as abordagens de argumentação desse polo não se situam mais do lado de uma pesquisa dos princípios da racionalidade do discurso, mas numa reflexão sobre os sentidos dos enunciados, seja por meio dos usos dos conectores e operadores argumentativos (teoria da "Argumentação na língua", de Oswald Ducrot), seja pela análise das esquematizações linguísticas em contexto natural de uso da língua ("Lógica natural”, de Jean-Blaise Grize) (PLANTIN, 2008, p. 16-17).

No âmbito da "Argumentação na língua", o sentido dos enunciados é dado pela intenção linguística do enunciador nas ligações, na língua, entre eles. Daí o interesse nessa teoria sobre os conectores e operadores argumentativos, dentre eles os operadores de comparação ("como", "menor/ muito menor", "tão [...] quanto", "mais [...] do que"). Vogt (1977, p. 89) salienta que a estrutura argumentativa de comparação contém dois movimentos contrários e simultâneos, um no sentido do favorável e outro no sentido do desfavorável. Pode-se dizer que existe entre os dois termos comparados uma espécie de oposição que, semanticamente, poderia ser identificada como uma negação da propriedade, que um dos termos absorve em desfavor do outro. O linguista também ressalta que na comparação o movimento argumentativo é sempre duplo e o que caracteriza a estrutura comparativa é a compensação entre os termos comparados (1977, p. 90).

Na seara da "Lógica natural", o discurso arquiteta uma "esquematização" na qual o ponto de vista é construído. Enfatiza-se nessa proposta os aspectos cognitivos da argumentação, que são desvelados na esquematização linguística. Como explica Grácio (2010, p. 204), a "Lógica natural” entende que a argumentação é da ordem da ordem da persuasão e nela não está em causa o valor de verdade do discurso, mas a verossimilhança daquilo que dá a ver através das suas esquematizações a um auditor/leitor que as reconstrói. Nesse sentido, a operação mental da comparação é tanto um esquema do pensamento, quanto da linguagem.

\subsection{ISD: linguagem, raciocínio lógico-comparativo, tipos discursivos e aprendizagem epistêmica}

O ISD, amparado na perspectiva interacionista de Vigotski, propõe uma análise argumentativa pelo viés da interação verbal, aproximando-se e obstando-se das perspectivas concentradas nos dois polos expostos anteriormente. 
Segundo Bronckart (2006), para o ISD, o problema da linguagem é absolutamente central, já que as práticas de linguagem situadas são instrumentos do desenvolvimento humano, tanto em relação aos conhecimentos e aos saberes quanto em relação às capacidades do agir. Ao centrar-se no papel da linguagem nas interações verbais concretas, o ISD se posiciona face às teorias da argumentação.

Em relação ao polo das boas razões, conhecido como paradigma clássico da argumentação, em que o silogismo é a forma canônica do raciocínio e definido como discurso lógico, o ISD, por um lado, observa que a linguagem não desempenha um papel central no desenvolvimento do raciocínio. Aliás, ela parece desempenhar por vezes um "papel negativo", na medida em que a linguagem, nessa perspectiva, poderia turvar os encadeamentos lógico-mentais (BOTA, 2011, p. 41). Por outro lado, o ISD aquiesce e ressalta a posição da Nova Retórica perelmaniana de que a linguagem é sempre mobilizada em função de um auditório e o discurso argumentativo deve ser adaptado à dada situação comunicativa (BOTA, 2018, p. 58-59).

Em relação ao polo lógico-linguístico, o ISD enfatiza, especialmente na proposta da "Lógica natural", uma proeminência das operações cognitivas face à dimensão da linguagem (BOTA, 2018, p. 75). Além disso, o qualificativo "natural" parece pleonástico, pois, segundo Bota (2011, p. 69), uma vez assumida a posição de que a linguagem deriva da interação humana, a palavra "natural" parece paradoxal. Em suma, o ISD busca enfatizar os parâmetros do contexto de produção não somente do ponto de vista do enunciador, mas também do interlocutor, compreendendo o lugar social assumido por ele na interação (BRONCKART, 1999).

O ISD, assim, propõe uma análise textual-argumentativa alicerçada tanto na psicologia soviética de vertente vigotskiana e na proposta de análise sociológica da linguagem de Vološinov, quanto nos pressupostos da Linguística Textual (LT) tal como iniciada na França e Suíça na década de 1970, especialmente pelos trabalhos de Michel Charolles, Denis Slakta, Jean-Michel Adam, Catherine Fuchs, entre outros. As pesquisas de Fuchs $(2014 ; 2019)$ evidenciam o mecanismo textual da comparação:

Fazer uma comparação é efetuar uma operação de pensamento que consiste em confrontar dois elementos (duas entidades, duas situações, ou uma mesma unidade considerada nas duas situações diferentes) a fim de estabelecer o que eles têm em comum e em que diferem [...] A comparação é, portanto, uma operação complexa, que coloca em questão processos cognitivos elaborados que participa da categorização [...] a propriedade comum que permite compará-los é chamada de "parâmetro" (FUCHS, 2019, p. 2, tradução nossa) ${ }^{2}$

2 No original: Faire une comparaison, c'est effectuer une opération de pensée qui consiste à confronter deux éléments (deux entités, deux situations, ou une même entité considérée dans deux situations différentes) afin d'établir ce qu'ils ont de commun et ce en quoi ils diffèrent [...] La comparaison est donc une opération complexe, qui met en 
A comparação do ponto de vista textual, como vemos acima, é tanto uma "operação do pensamento", quanto uma "operação de linguagem", visto que ela constrói categorizações. Estas, de acordo com Fuchs (2019, p. 9), são sempre avaliativas, pois carregam uma conotação positiva ou negativa que "provoca discursivamente efeitos de sentidos diferentes"3.

Além dessas balizas, a comparação é analisada no ISD à guisa da proposta metodológica de Vološinov (2010 [1929]). Assim, examina-se primeiramente o quadro contextual no qual a interação se realiza, composto de parâmetros físicos e sociossubjetivos (BRONCKART, 1985; 1999). Posteriormente, segundo Bronckart (1999; 2006), analisa-se a infraestrutura geral do texto, composta pelo plano mais geral, isto é, a organização do conjunto dos conteúdos temáticos e os tipos discursivos. Depois, os mecanismos de textualização (conexão, coesão nominal e coesão verbal) e, por fim, os mecanismos de responsabilização enunciativa (vozes e modalizações). A seguir, enfocaremos o conceito de tipos discursivos, categoria proposta pelo ISD e pela qual é possível examinarmos o raciocínio comparativo nas análises que proporemos neste artigo.

Os tipos discursivos podem ser definidos como configurações particulares de unidades e de estruturas linguísticas, em número limitado, que podem entrar na composição de todo o texto. Mais do que somente estruturas linguísticas, Bronckart (2006, p.154) os define como estruturas psicolinguageiras, pois os tipos discursivos exprimem mundos discursivos que colocam em interface representações individuais e representações coletivas (que têm sua sede nas obras humanas).

Os tipos discursivos comportam um conjunto de operações linguísticas e mobilizam, quando acionados, formas mentais ou raciocínios (BRONCKART, 2006, p. 154). Conforme entendem Bulea e Bronckart (2008), os tipos discursivos desenvolvem diversas formas de raciocínio humano: raciocínio causal/temporal (no relato interativo e narração), raciocínio prático do senso comum (no tipo discurso interativo) e raciocínio lógico (no tipo de discurso teórico). Em nossas análises verificaremos o raciocínio lógico-comparativo na mobilização dos tipos discursivos.

Há quatro tipos discursivos: o "discurso teórico" e o "discurso interativo" referentes ao mundo discursivo da ordem do expor, e os tipos discursivos "narração" e "relato interativo" referentes à ordem do narrar (BRONCKART, 1999). Trataremos dos dois tipos discursivos da ordem do expor, pois são eles que nos permitem interpretar nossos dados. O tipo discursivo interativo possibilita a criação de segmentos nos quais há implicação conjunta dos participantes da interação verbal, que trocam informações entre

jeu des processus cognitifs élaborés participant de la catégorisation [...] la propriété commune qui permet de les comparer est appelée le 'paramètre' (FUCHS, 2019, p. 2)

3 No original: [...] donne lieu en discours à des effets de sens différents. (FUCHS, 2019, p. 9). 
si, como verificamos em sequências dialogais orais ou escritas. Por essa razão, encontramos, no discurso interativo, dêiticos pessoais, espaciais e temporais, além de marcadores conversacionais e os tempos verbais presente e passado composto.

O tipo discursivo teórico, por sua vez, pode criar um mundo discursivo em que não há implicação do agente produtor do texto e apagamento dos parâmetros de produção. Encontramos geralmente os tempos verbais presente e passado composto, como também o presente gnômico, além da presença de inúmeros organizadores lógicoargumentativos, grande número de modalizações lógicas e de anáforas nominais; no mais, verificamos procedimentos de referência (metatextual, intratextual e intertextual) ao próprio texto ou ao intertexto científico.

Na verdade, segundo Bronckart (2006), é no nível dos tipos discursivos que se implementam os processos de mediação que contribuem para o desenvolvimento das propriedades principais das pessoas (como a construção da identidade, a inserção no tempo, o domínio dos raciocínios, entre outros), pois, se por um lado permitem a mediação de processos mentais - os raciocínios - por outro ela só é possível pelas propriedades do sistema da língua, que limita fortemente a mediação. Assim, a mediação pela linguagem se constitui como um processo de desenvolvimento fundamental, na medida em que é por meio dela que se transmite as grandes formas da operatividade do pensamento humano.

Um dos focos do ISD é a investigação das formas de transmissão dos saberes, ou seja, o modo pelo qual os membros mais experientes do grupo integram e transmitem os produtos materiais e mentais da cultura. No âmbito do interacionismo sociodiscursivo, essa questão também é discutida a partir dos trabalhos de Vigotski, investigando-se os "sistemas formativos". Conforme detalham Bulea, Bota e Bronckart (2006, p. 51), os "sistemas formativos" podem ser agrupados em processos de educação desenvolvidos no meio escolar ou em outros processos nos quais os indivíduos mais experientes integram os recém-chegados no conjunto de pré-construídos coletivos, desenvolvendo conjuntamente atividades e mostrando as normas e os valores sociais, quando lhes são fornecidos comentários verbais sobre essas atividades.

$\mathrm{Na}$ perspectiva do ISD, os pré-construídos coletivos, como os verdadeiros conceitos, por exemplo, não podem se autoproduzir (BULEA; BOTA; BRONCKART, 2006). Na perspectiva vigotskiana, o conceito verdadeiro pode ser comparado, segundo Bota (2018), a um "diamante esculpido", logo há "filigranas" constituintes a serem aprendidas. Desse modo, as capacidades epistêmicas não são desenvolvidas naturalmente, pois os conceitos científicos só podem ser apropriados se houver uma aprendizagem epistêmica para tal (BOTA, 2018).

Nesse sentido, esse tipo de aprendizagem deve ser produzido necessariamente dentro de uma mediação formativa, pois ele não pode emergir espontaneamente ou se 
autoproduzir no aprendiz (BOTA, 2018, p. 224). Assim sendo, investigaremos a capacidade que o "aprendiz" - os mestrandos em formação no nosso caso - adquire para fazer interagir o pensamento e a linguagem, a fim de se apropriar dos conceitos e raciocinios disponibilizados pelo dispositivo de formação.

\section{Metodologia da Pesquisa}

Nosso contexto mais geral de pesquisa foi a Universidade de São Paulo, mais especificamente a Faculdade de Filosofia, Letras e Ciências Humanas. Para encontrarmos nossos sujeitos de pesquisa, elaboramos um questionário para verificar: quais mestrandos consentiam em participar do estudo; quais estavam num estágio da pesquisa que nos permitiria ter os dados de que necessitávamos. Após a aplicação de um questionário, três mestrandos se mostraram aptos a serem os participantes de nosso estudo. Eles pertenciam a três programas de pós-graduação da Faculdade de Letras, são eles: Estudos linguísticos, literários e tradutológicos em Francês; Filologia e Língua Portuguesa; Língua e Literatura Italiana.

Os três participantes estavam elaborando as suas pesquisas, quando aceitaram participar de nosso estudo, concedendo-nos seus textos e versões dos projetos, relatórios de qualificação e, posteriormente, tivemos acesso às dissertações de mestrado e versões.

O Estudante 1 é bacharel em Letras (português/francês) e foi mestrando no Programa de pós-graduação em Estudos Linguísticos, Literários e Tradutológicos em Francês. O objetivo da sua pesquisa foi estudar as mediações formativas de correção linguageira por meio de ferramentas digitais entre alunos brasileiros e canadenses de níveis diferentes de francês e sua influência no desenvolvimento da produção escrita de gêneros textuais dos alunos brasileiros.

Por seu turno, o Estudante 2 possui bacharelado e licenciatura em Letras (português/francês) e foi mestrando no Programa de pós-graduação em Filologia e Língua Portuguesa. O objetivo da pesquisa foi analisar e descrever, através da Linguística Sistêmico-Funcional e da Semiolinguística, as formas de representação do Movimento Estudantil ativo no Estado de São Paulo, verificadas em notícias produzidas pela Folha de S. Paulo e Estado de S. Paulo, em três períodos distintos: 1968, 1977 e 2011.

Por fim, o Estudante 3 é licenciado em Letras (italiano) e foi mestrando no Programa de pós-graduação em Língua e Literatura Italiana. O objetivo da pesquisa foi investigar as contribuições de aspectos culturais para o ensino de língua de herança, através do planejamento e aplicação de um curso de língua italiana em contexto de 
língua de herança, na comunidade do município de Pedrinhas Paulista/SP, com ênfase em produção de materiais didáticos.

Neste artigo, como explicamos na introdução, focaremos em alguns excertos mais representativos das nossas análises dos textos escritos. Posto que estávamos trabalhando com as versões dos textos produzidos pelos estudantes, recebemos uma vultosa quantidade de dados escritos, os quais tivemos que uniformizar metodologicamente. Em linha gerais, selecionamos as versões com mais comentários dos orientadores e que guardavam, também, comentários de versões anteriores.

Dentre esses comentários, interessavam-nos aqueles acerca dos conceitos teóricos usados pelos estudantes, na seção de "Fundamentação teórica" e nas sínteses interpretativas elaboradas por eles, na seção de "Análises e resultados".

Apontamos, na seção anterior, a nossa adesão ao ISD tanto no plano teórico, quanto da análise metodológica. Dentre as categorias de análise propostas pelo ISD, selecionamos, neste artigo, os tipos discursivos, particularmente o discurso interativo e o discurso teórico, que foram encontrados em nossos dados e possibilitam uma reflexão sobre o desenvolvimento dos mestrandos nesse processo formativo. Os raciocínios lógico-comparativos particularmente encontrados nas seções de "Análises e resultados" das pesquisas nos parecem relevantes, pois permitem compreender tanto o processo de aprendizagem epistêmica dos estudantes durante o mestrado, quanto discutir sobre a compreensão dos conhecimentos que as pesquisas aportam para determinado grupo ou teoria científica.

Por isso, em primeiro lugar, analisaremos alguns excertos que permitem compreender o processo da aprendizagem epistêmica por meio da modificação e reformulação das exposições teóricas dos estudantes, após os comentários verbais de seus orientadores. ${ }^{4}$ Esse procedimento é relevante, pois estamos trabalhando com as versões dos textos escritos, as quais contêm diversos comentários dos orientadores, logo é pertinente para nós discutir o aspecto formativo dessas intervenções, contrastando com as mudanças apresentadas no raciocínio produzido nas versões finais dos textos, após os comentários formativos.

Em seguida, buscaremos evidenciar que os raciocínios lógico-comparativos encontrados nas seções de "Análises e resultados" apontam a maneira pela qual os estudantes estão mobilizando os conceitos teóricos aprendidos ao longo do mestrado, a fim de organizar processos mentais de sínteses interpretativas (generalizações).

\footnotetext{
${ }^{4}$ Os comentários dos orientadores estão marcados entre colchetes negritados: [comentário do orientador].
} 


\section{Análises}

Os três exemplos que analisaremos a seguir, similares a outros identificados em nossos dados de pesquisa, são representativamente importantes. Eles permitem perceber de modo geral que os raciocínios lógico-comparativos encontrados nas seções de "Análises e resultados" das pesquisas são formulados tendo como "parâmetro" (FUCHS, 2019) os conceitos teóricos aprendidos pelos estudantes ao longo do processo de mestrado, nas várias interações verbais entre eles e os orientadores, tanto nas versões dos projetos de pesquisa, quanto nas versões dos relatórios de qualificação e dissertações. Vejamos os exemplos 1, 2 e 3 no Quadro 1.

\section{Quadro 1 - Aprendizagem epistêmica ao longo do mestrado acadêmico}

\begin{tabular}{|c|c|c|}
\hline \multirow[b]{3}{*}{ 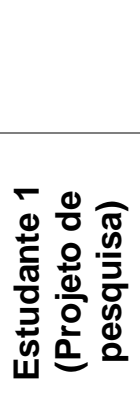 } & \multicolumn{2}{|c|}{ Excertos - Seção de “Fundamentação teórica” } \\
\hline & Versão comentada & Versão Final \\
\hline & $\begin{array}{l}\text { "Os gêneros [cuidado pq Bakthin não } \\
\text { usa o termo gênero textual] são [...] } \\
\text { enunciados relativamente estáveis } \\
\text { presentes em cada esfera da atividade } \\
\text { humana e sócio-historicamente } \\
\text { construídos (BAKHTIN, 1953)." }\end{array}$ & $\begin{array}{l}\text { "Os gêneros do discurso são [...] } \\
\text { enunciados relativamente estáveis } \\
\text { presentes em cada esfera da } \\
\text { atividade humana e sócio- } \\
\text { historicamente } \\
\text { (BAKHTIN, 1953)." }\end{array}$ \\
\hline 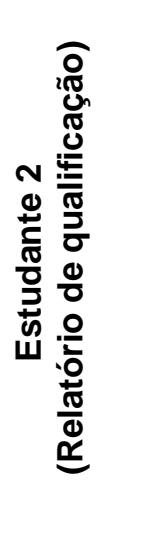 & $\begin{array}{l}\text { Outro componente constituinte das C de D } \\
\text { é a Situação extralinguística, que se } \\
\text { constrói por meio do ambiente material } \\
\text { relativo à codificação ou à decodificação } \\
\text { da mensagem. Tal ambiente é pertinente } \\
\text { ao fato de que os sujeitos da troca são } \\
\text { possuidores do mesmo saber a respeito do } \\
\text { mundo que os envolve, e por conta disso, } \\
\text { esse ambiente pode ser "transformado em } \\
\text { palavras". [Não está clara a noção. } \\
\text { Parece que a situação extralinguística } \\
\text { se refere ao espaço físico. É só isso } \\
\text { mesmo?]. }\end{array}$ & $\begin{array}{l}\text { Ademais, outro componente } \\
\text { constituinte das C de D é a Situação } \\
\text { extralinguística, que se "figura como } \\
\text { um ambiente material transformado } \\
\text { em palavra através dos filtros } \\
\text { construtores de sentido, utilizados } \\
\text { pelos atores da linguagem" } \\
\text { (CHARAUDEAU, 2014, p. 32). Assim, } \\
\text { esses atores também criam hipóteses } \\
\text { segundo as quais um determinado } \\
\text { ambiente semiotizado está inserido } \\
\text { em um saber partilhado. }\end{array}$ \\
\hline 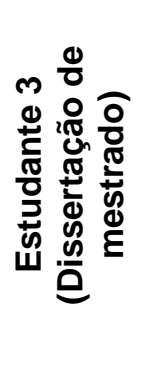 & $\begin{array}{l}\text { Ortale (2016) entendeu que os conceitos } \\
\text { de Língua de Herança (LH) até então por } \\
\text { nós conhecidos, ou seja, tendo o critério } \\
\text { de ancestralidade ou de proficiências } \\
\text { como central [e que define a } \\
\text { ancestralidade ou a proficiência como } \\
\text { critério central], não davam conta da } \\
\text { situação que se apresentava, redefinindo } \\
\text { o conceito [está sem coesão]. }\end{array}$ & $\begin{array}{l}\text { Ortale (2016) entendeu que os } \\
\text { conceitos de Língua de Herança (LH) } \\
\text { até então por nós conhecidos, e que } \\
\text { definem a ancestralidade ou a } \\
\text { proficiência como critério central, não } \\
\text { davam conta da situação que se } \\
\text { apresentava. }\end{array}$ \\
\hline
\end{tabular}

Fonte: Elaboração do autor 
Nos exemplos 1, 2 e 3 (Quadro 1), é possível perceber as interações formativas entre orientandos e orientadores em relação aos conceitos teóricos das pesquisas. Os exemplos são representativos de diversos outros encontrados e analisados por nós, identificáveis durante todo o percurso do mestrado (inicial, intermediário e final), quer nas exposições teóricas dos projetos, quer nos relatórios de qualificação e dissertações. Nos exemplos acima, encontramos características psicolinguísticas típicas dos tipos discursivos teórico e interativo (BRONCKART, 1999).

No Exemplo 1, verificamos o uso do presente gnômico ("são" e "usa"), do termo com sentido vocativo ("cuidado"), cujo efeito pressupõe um "diálogo" com o destinatário, modalização lógica expressa por uma asserção ("Bakhtin não usa"), além de organizadores lógicos ("e" e "porque"). O trabalho do Estudante 1 foi baseado na perspectiva dos gêneros textuais. Contudo, ao definir esse conceito, na "Fundamentação teórica", o mestrando o faz por meio da definição de outro conceito, de gêneros do discurso. A partir do Exemplo 1, levantamos a hipótese de que o estudante tomou os dois conceitos como semelhantes, associando-os por um vínculo com baixo grau de abstração. Podemos supor que o estudante compreendia naquele momento os dois conceitos, gêneros textuais e gêneros do discurso, como sinônimos.

Nas fases intermediárias e finais do mestrado, em inúmeros excertos de nossas análises dos relatórios de qualificação e dissertações, encontramos uma elevada quantidade de conceitos em maturação. Isso pode nos indicar que há vários conceitos cuja aprendizagem é mais complexa e, geralmente, os estudantes apresentam algumas dificuldades de se apropriar de todos os atributos constituintes dos conceitos. Todavia, suas explicações parecem críveis, quando se analisa de forma superficial. Vejamos os excertos abaixo, Exemplos 2 e 3.

No Exemplo 2, verificamos marcas do tipo discursivo interativo e teórico (BRONCKART, 1999). Encontramos uma pergunta que remete diretamente a um "diálogo" com o interlocutor (“É só isso mesmo?"), organizadores lógicos (“Outro”, "por conta disso"), modalização lógica ("Não está clara”), anáfora de referenciação intratextual ("Tal", "esse"). No Exemplo 2, o mestrando expõe o conceito de "Situação extralinguística" pertencente à teoria Semiolinguística, explicando quais atributos 0 constituem. Face a isso, o orientador comenta a exposição elaborada, afirmando que ela não está devidamente formulada, como verificamos em "Não está clara a noção". Podemos pensar que, do ponto de vista do orientador, a exposição do estudante abarcou somente um aspecto do conceito, porém há outros que o compõem.

O Exemplo 3, igualmente aos dois anteriores, também evidencia um diálogo entre o mestrando e o orientador. Os comentários do orientador intervêm no discurso teórico da exposição do estudante, com a finalidade de ajustá-lo conceitualmente. Vale ressaltar que o conceito de "língua de herança" é axial na pesquisa do Estudante 3. 
Em resumo, os Exemplos 1, 2 e 3 mostram que, ao longo do processo do mestrado, ocorre uma aprendizagem epistêmica por meio das interações verbais entre os estudantes e os orientadores, especialistas em determinada linha teórica. Como veremos nos próximos três exemplos, os conceitos teóricos aprendidos podem funcionar como "parâmetros" (FUCHS, 2019) para a construção de sínteses interpretativas (generalizações) encontradas nas seções de "Análises e resultados" tanto dos relatórios de qualificação, quanto das dissertações de mestrado. Isso pode ser examinado pelos raciocínios lógico-comparativos elaborados pelos estudantes. Observemos os exemplos 4, 5 e 6 no Quadro 2.

Quadro 2 - Raciocínios lógico-comparativos - fase intermediária e final do mestrado

\begin{tabular}{|c|c|c|}
\hline & \multicolumn{2}{|c|}{ Excertos - Seção de "Análises e resultados" } \\
\hline & Ideias síntese das análises & Raciocínios lógico-comparativos \\
\hline 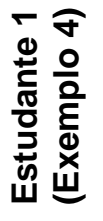 & $\begin{array}{l}\text { Seu comentário "je suis contente d'avoir la } \\
\text { possibilité d'échange avec des étudiants } \\
\text { Canadiens" configura-se }[\ldots]\end{array}$ & $\begin{array}{l}\text { como um ato de polidez } \\
\text { positiva } \\
\text { ORECCHIONI, 1996). }\end{array}$ \\
\hline 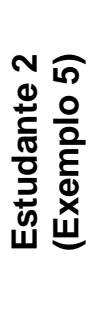 & $\begin{array}{l}\text { Os exemplos (3) e (4) relevam uma outra faceta: } \\
\text { as expectativas sociais acerca da atividade policial } \\
\text { na manifestação, uma vez que o marcador de } \\
\text { polaridade não é o verbo deixar, marcam aquilo } \\
\text { que as vozes institucionais projetavam [...] } \\
\text { Especialmente no Estado de São Paulo, a Polícia } \\
\text { é construída reiteradamente [...] }\end{array}$ & $\begin{array}{l}\text { como Processos Materiais } \\
\text { típicos dos agentes do Estado } \\
\text { [...] como um Ator ineficiente ou } \\
\text { inerte, responsável. }\end{array}$ \\
\hline 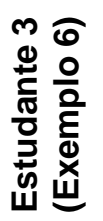 & $\begin{array}{l}\text { Já a Tradição Oral tornou-se a espinha dorsal do } \\
\text { material, tendo em vista que ela se configura [...] }\end{array}$ & $\begin{array}{l}\text { como um importante veículo } \\
\text { de transmissão das tradições } \\
\text { e da cultura italiana para os } \\
\text { alunos. }\end{array}$ \\
\hline
\end{tabular}

Fonte: Elaboração do autor

Primeiramente, o tipo discursivo teórico é marcado nos três excertos acima pelo conector lógico de comparação "como", entre outros, além de formas verbais no presente gnômico ("configura-se", "revelam") e no particípio ("construída").

Nos exemplos acima, podemos constatar, na coluna à esquerda, que os estudantes estão interpretando as análises dos dados de suas pesquisas. O Estudante 1 analisava interações corretivas de textos entre alunos de língua francesa, brasileiros e canadenses; a Estudante 2 analisava textos jornalísticos sobre atuações de movimentos estudantis; a Estudante 3 analisava histórias de vida relatadas por alunos 
de um curso de língua italiana como língua de herança. À direita, as análises são retomadas por expressões iniciadas pelo termo comparador "como".

O Exemplo 4 possibilita entrever que o Estudante 1 analisava interações corretivas síncronas entre estudantes brasileiros e canadenses de língua francesa. Dentre os comentários dessas interações, o mestrando interpreta que um deles é diferente e, para marcar essa diferenciação, adota como parâmetro (FUCHS, 2019) o conceito de "Atos de Ameaça à Face", oriundo dos estudos em Análise da Conversação. O raciocínio lógico-comparativo "como um ato de polidez positiva (KERBRAT-ORECCHIONI, 1996)" concretiza essa síntese interpretativa. Segundo Perelman e Olbrechts-Tyteca (2005, p. 274-275), as comparações dão concretude àquilo que é uma abstração. Assim, podemos supor por este exemplo e os próximos que as comparações têm uma função de evidenciar de forma clara e concreta as relações de semelhança encontradas em um certo conjunto de dados.

No Exemplo 5, ao analisar um conjunto de dados, que foi exemplificado pelos excertos (3) e (4) de sua pesquisa, o mestrando se vale de um raciocínio lógicocomparativo ("como Processos Materiais típicos dos agentes do Estado [...] como um Ator ineficiente ou inerte, responsável"), a fim de mostrar uma similaridade entre os excertos e sua funcionalidade. A nossa hipótese é que os raciocínios comparativos construídos pelos estudantes têm como "parâmetro" (FUCHS, 2019) os conceitos teóricos ("Processos Materiais" e "Ator"), da Linguística Sistêmico-Funcional, aprendidos por eles nas interações formativas com os seus orientadores. Relembremos os Exemplos 1, 2 e 3 (Quadro 1), ao solicitar a reformulação das exposições teóricoconceituais, os orientadores propiciam aos mestrandos momentos de maior aprendizagem epistêmica.

No Exemplo 6, o estudante discorria sobre os resultados das análises das histórias de vida nos módulos do curso de língua de herança. Segundo ele, de acordo com cada tema tratado - imigração italiana, imigração na Itália atual, comida, dialetos - pensavase em qual imigrante poderia ser convidado para trazer boas histórias sobre o tema. Os alunos-cursistas participavam das entrevistas ativamente, fazendo perguntas conforme as histórias contadas despertavam curiosidades. No Exemplo 6, acima, o conjunto de histórias de vida durante as atividades do curso de italiano como língua de herança foi reunido a partir do mesmo parâmetro (FUCHS, 2019), ou seja, "como elemento fundamental para a reconstrução da identidade dos alunos". Esse parâmetro advém do conceito teórico central da pesquisa do Estudante 3: língua de herança (Quadro 1).

Em síntese, os raciocínios lógico-comparativos que verificamos em dezenas de ocorrências nas seções de "Análises e resultados" das pesquisas não podem ser analisados somente do ponto de vista clássico da argumentação, mas também da 
perspectiva interacional-formativa entre os pesquisadores mais e menos experientes prevista na formação em mestrado acadêmico.

Para finalizar nossas análises, examinaremos o Exemplo 7 (Quadro 3), o qual a nosso ver contém uma particularidade na discussão que estamos aqui conduzindo sobre os raciocínios lógico-comparativos.

Encontramos um exemplo, na versão final da dissertação de mestrado do Estudante 1, a partir do qual levantamos a hipótese de que se trata de um raciocínio lógico-comparativo diferente dos outros. No excerto abaixo, veremos que o mestrando mostra uma aprendizagem razoável de noções pertencentes a um mesmo sistema conceitual, utilizando-as a fim de produzir um raciocínio comparativo sobre os dados de análise da sua pesquisa. O mestrando parece propor uma nova categoria analítica, a qual foi por ele nomeada.

No Quadro 3, vemos, na coluna da esquerda, o raciocínio lógico elaborado pelo estudante e, na da direita, propomos uma interpretação do que observamos.

Quadro 3 - Raciocínio lógico-comparativo e a construção dos saberes

\begin{tabular}{|c|c|}
\hline \multicolumn{2}{|c|}{ Excerto - Seção de "Análises e resultados" } \\
\hline Raciocínio lógico comparativo & Nossa interpretação \\
\hline $\begin{array}{l}\text { "A correção assíncrona realizada por Camila no } \\
\text { GoogleDocs ao texto do gênero fait divers foi diferente } \\
\text { de todas as outras feitas pelos outros } 5 \text { alunos } \\
\text { canadenses [...]" }\end{array}$ & $\begin{array}{l}\text { 1. O Estudante } 1 \text { se depara com } \\
\text { uma situação-problema (incomum) } \\
\text { que foi encontrada nas análises dos } \\
\text { seus dados de pesquisa. }\end{array}$ \\
\hline $\begin{array}{l}\text { "Se usarmos a nomenclatura proposta pelos autores } \\
\text { brasileiros Serafini (1989) e Ruiz (2010) que falam } \\
\text { sobre correção e que apresentamos em nosso capítulo } \\
\text { teórico, podemos chamar seu modo de corrigir de } \\
\text { "correção resolutiva". Entretanto, devemos ressaltar } \\
\text { que o que foi feito pela aluna canadense não coincide } \\
\text { exatamente com a definição desse conceito [...] } \\
\text { Enquanto as pesquisas realizadas até então tratam de } \\
\text { correções feitas no papel, não há um conceito que } \\
\text { corresponda ao que encontramos em nosso corpus, } \\
\text { cujos dados foram gerados a partir de ferramentas } \\
\text { digitais. O mesmo acontece com o conceito de } \\
\text { "emenda" desenvolvido por Tapia (2016) [...]" }\end{array}$ & $\begin{array}{l}\text { 2. Após os conceitos terem sido } \\
\text { aprendidos pelo Estudante 1, ele } \\
\text { não encontra na literatura } \\
\text { especializada um conceito } \\
\text { adequado para compreender a } \\
\text { situação-problema. }\end{array}$ \\
\hline $\begin{array}{l}\text { Poderíamos ter algo parecido em um suporte físico, se } \\
\text { pensarmos em uma correção que usa a mesma cor de } \\
\text { caneta que o texto original e não usa nenhum outro } \\
\text { recurso semiótico para mostrar ao autor daquele texto } \\
\text { os contornos da correção. Seu modo de corrigir se } \\
\text { configura como uma "correção camuflada". }\end{array}$ & $\begin{array}{l}\text { 3. O Estudante } 1 \text { elabora um } \\
\text { pensamento original a partir dos } \\
\text { conceitos aprendidos. }\end{array}$ \\
\hline
\end{tabular}

Fonte: Elaboração do autor 
Nesse raciocínio lógico elaborado pelo estudante não havia comentário na versão comentada pelo orientador. As características do discurso teórico aparecem na alta densidade de organizadores lógico-argumentativos ("Entretanto", "Enquanto", "A partir de", entre outros), referência ao intertexto científico ("Se usarmos a nomenclatura proposta pelos autores brasileiros Serafini (1989) e Ruiz (2010) que falam sobre correção", "correção resolutiva", "emenda"), referência intratextual ("que apresentamos em nosso capítulo teórico"), anáforas pronominais e nominais ("seu modo de corrigir", "algo", "como uma correção camuflada").

Parece-nos que a expressão "como uma correção camuflada" proposta pelo aluno pode funcionar como uma retomada sintética de uma generalização, decorrente dos processos de aprendizagem epistêmica acionados ao longo da formação no mestrado. Poderíamos arriscar afirmar que constatamos uma aprendizagem epistêmica com elevado grau de abstração, mais consistente, na qual o processo de aprendizagem permite não somente a uma produção de certas conexões localizadas (ou momentâneas) entre o pensamento e a linguagem, porém a uma capacidade contínua de realizar tais conexões, afetando outros conhecimentos interiorizados anteriormente. Tomando a ideia de que a comparação sempre comporta um "parâmetro" avaliador (FUCHS, 2019), é possível pensar que o Estudante 1 não se valeu somente de um conceito teórico, mas de um sistema conceitual como "parâmetro" para a construção do raciocínio lógico-comparativo, sintetizado em "como uma correção camuflada".

Levantamos a hipótese que o Estudante 1 foi capaz de reconstruir um sistema de conceitos aberto, sendo capaz de "ultrapassar" seus atributos, a fim de "realimentar" o sistema conceitual do qual partiu, sugerindo uma nova categoria. Contudo, não podemos afirmar peremptoriamente que o termo "correção camuflada" é um conceito verdadeiro, pois essa certificação precisa ser realizada pelos especialistas no domínio conceitual apresentado pelo mestrando em sua pesquisa.

\section{Considerações finais}

As análises empreendidas neste artigo permitem-nos levantar algumas considerações sobre os raciocínios lógico-comparativos encontrados nas sínteses interpretativas dos mestrandos, sobretudo nas seções de "Análises e resultados" das pesquisas dos relatórios de qualificação e dissertações.

Os raciocínios lógico-comparativos que analisamos parecem ter relação com a aprendizagem epistêmica pela qual os mestrandos são submetidos durante toda a formação do mestrado. Os orientadores, especialistas em determinadas correntes 
teóricas, comentam as exposições escritas dos estudantes, levando-os a revisarem um determinado conceito, a fim de que este seja apresentado em conformidade com as representações dos especialistas.

Nas fases intermediárias e finais das pesquisas, os três estudantes demonstraram utilizar os conceitos científicos aprendidos para elaborar processos generalização e abstração das análises e resultados dos estudos, expressos textualmente pelos raciocínios lógico-comparativos. Na fase final, na dissertação de mestrado, constatamos em nossas análises que a possível noção de "correção camuflada", elaborada pelo Estudante 1, é o produto de um raciocínio lógico pelo qual o mestrando, diante de uma situação-problema verificada nas suas análises, não consegue compreender seus dados, pois os conceitos adotados não dão conta de explicar a peculiaridade encontrada. Assim, o estudante se vale da situação concreta na qual os conceitos foram elaborados, usando-os em outra, de modo a modificar os seus atributos e, consequentemente, produzir algo novo.

Cientes das restrições metodológicas de nossa proposta, acreditamos que os resultados a que chegamos podem lançar luzes sobre a importância da análise da formação e desenvolvimento do pesquisador, bem como contribuir para a compreensão da construção do pensamento científico, especificamente da construção dos saberes.

\section{Referências}

ARISTOTE. Rhétorique. Tradução: Norbert Bonafous. Paris: A. Durand, 1856. Disponível em: https://gallica.bnf.fr/ark:/12148/bpt6k6342639k/f267.item. Acesso em: 30 nov. 2021.

BOTA, Cristian. Savoirs, textes et apprentissages en milieu universitaire. Pour une analyse sociodiscursive de travaux de validation pour les cours. 2011. Tese (Sciences de l'Éducation) - Universidade de Genebra, Genebra, 2011.

BOTA, Cristian. Pensée verbale et raisonnement: les fondements langagiers des configurations épistémiques. 1.ed. Berna: Peter Lang, 2018.

BRONCKART, Jean-Paul et al. Le fonctionnement des discours: Un modèle psychologique et une méthode d'analyse. Neuchâtel: Delachaux \& Niestlé, 1985.

BRONCKART, Jean-Paul. Atividade de linguagem, textos e discursos: por um Interacionismo Sociodiscursivo. 2.ed. Tradução: Anna Rachel Machado e Péricles Cunha. São Paulo: Educ, 1999.

BRONCKART, Jean-Paul. Atividade de linguagem, discurso e desenvolvimento humano. 1.ed. Tradução: Anna Rachel Machado e Maria Lucia Meirelles Matêncio. Campinas: Mercado de Letras, 2006.

BULEA, Ecaterina; BOTA, Christian; BRONCKART, Jean Paul. L'épistémologie nébuleuse de l'autoformation. Education permanente, n. 168, p. 31-57, 2006. 
BULEA, Ecaterina; BRONCAKRT, Jean-Paul. As potencialidades praxiológicas e epistêmicas dos (tipos de) discursos. SCRIPTA, v. 22, n. 12, p. 42-83, 2008.

FERREIRA-SANTOS, Thiago Jorge. Textos, aprendizagem e desenvolvimento do pesquisador no processo formativo do mestrado acadêmico. 2020. Tese (Doutorado em Letras) - Faculdade de Filosofia, Letras e Ciências Humanas, Universidade de São Paulo, São Paulo, 2020. Disponível em: https://doi.org/10.11606/T.8.2020.tde-18082020172140. Acesso em: 19 jan. 2022.

FIORIN, José Luiz. Argumentação. 1ed. São Paulo: Contexto, 2015.

FUCHS, Catherine. La comparaison et son expression en français. Paris: Éditions Ophyrs, 2014.

FUCHS, Catherine. La Comparaison: une catégorie linguistique multiforme. In: COLLOQUE INTERNATIONAL D'ÉTUDES FRANCOPHONES "COMPARAISON(S)", 2019, Timisoara, Roumanie. Anais [...]. Disponível em: https://hal.archives-ouvertes.fr/hal-03044077. Acesso em: 30 nov. 2021.

GRÁCIO, Rui Alexandre. Para uma teoria geral da argumentação: questões teóricas e aplicações didácticas. 2010. Tese (Doutorado em Ciências da Comunicação) - Instituto de Ciências Sociais, Universidade do Minho, Braga, 2010.

PERELMAN, Chaïm; OLBRECHTS-TYTECA, Lucie. Tratado da argumentação: a Nova Retórica. Tradução: Maria Ermantina Galvão. 6. ed. São Paulo: Martins Fontes, 2005.

PLANTIN., Christian. A argumentação biface. In: LARA, Glaucia Muniz Proença; MACHADO, Ida Lucia; EMEDIATO, Wander (org.). Análises do discurso hoje. v. 2. Rio de Janeiro: Nova Fronteira, 2008. p. 13-26.

RINCK, Fanny. Análise Linguística dos desafios de conhecimento no discurso científico: um panorama. In: RINCK, Fanny; BOCH, Françoise; ASSIS, Juliana Alves. Letramento e formação universitária: formar para a escrita e pela escrita. 1.ed. Campinas: Mercado de Letras, 2015. p. 57-95.

SILVA, Maria Suely Fernandes da. O mestrado em educação da UEL: um estudo das dissertações 1995-2006. 2008. Dissertação (Mestrado em Educação) - Universidade Estadual de Londrina, Londrina, 2008.

SOMENSI, Neura Fazolo. Variáveis que influenciam 0 desenvolvimento do conhecimento no curso de mestrado, na percepção dos egressos. 2005. Dissertação (Mestrado em Administração) - Universidade Federal de Santa Catarina, Florianópolis, 2005.

VOGT, Carlos. O intervalo semântico: Contribuição para uma Teoria Semântica Argumentativa. 1.ed. São Paulo: Ática, 1977.

VOLOŠINOV, Valentin Nikolaevic. Marxisme et philosophie du langage: Les problèmes fondamentaux de la méthode sociologique dans la science du langage. Tradução: Patrick Sériot e Inna Tylkowski-Ageeva. Limoges: Lambert Lucas, 2010. 